\title{
Electromyography Signal Analysis of the Fencing Lunge by Magda Mroczkiewicz, the Leading World Female Competitor in Foil
}

DOI: $10.2478 / \mathrm{v} 10131-011-0017-1$

Authors' Contribution: A - Study Design

B - Data Collection

C - Statistical Analysis

D - Data Interpretation

E - Manuscript Preparation

$\mathrm{F}$ - Literature Search

$\mathrm{G}$ - Funds Collection

\author{
Andrzej Suchanowski ${ }^{1}$ (A, G) Zbigniew Borysiuk $^{2}$ (B, D), \\ Paweł Pakosz ${ }^{2}$ (C, E, F) \\ ${ }^{1}$ Jędrzej Śniadecki Academy of Physical Education and Sport in Gdańsk, Poland \\ ${ }^{2}$ Faculty of Physical Education and Physiotherapy, Opole University of Technology, \\ Poland
}

Key words: fencing lunge, EMG signal, movement duration

Material/Methods: radialis of the right arm and rectus femoris of lower extremities.

\section{Abstract}

Background: Fencing lunge is the most important element of the fencing footwork technique. The aim of this study was to determine the dynamic model of the fencing lunge made by an experienced athlete, based on the EMG record of muscles activity: extensor carpi the 2011 season. To assess muscle involvement in the movement the electromyography (EMG) method was used. A device manufactured by NORAXON with MyoResearch XP MT400 software was utilized.

Results: During the fencing lunge, muscle activation starts from the rear lower extremity, then the attacking arm, and finally the front lower extremity. The average EMG stimulation was the largest in the rear lower extremity and the smallest one in the attacking arm.

Conclusions: The research shows that top-class athletes start the fencing lunge from tension in muscles of the rear lower extremity. Moreover, stimulation of the weapon arm and rear lower extremity muscles indicates their synchronization, whereas the front lower extremity works asynchronously.

Word count: 993

Tables: -

Received: July 2011

Figures: 1

Accepted: September 2011

References: 5

Published: October 2011

Address for correspondence:

Mgr Paweł Pakosz

Faculty of Physical Education and Physiotherapy, Opole University of Technology

UI. Prószkowska 76, 45-758 Opole

Phone: + 48607850020, fax: + 48774000418, e-mail: p.pakoszl@po.opole.pl 


\section{Introduction}

Fencing lunge is one of the fencer's basic movements on the piste. It is the most important component of the footwork technique. Therefore, together with fencing steps and jumps it constitutes the main element, beside the balestra, of offensive action [1]. Fencing lunge, as a motor program, involves two phases: offensive action, ended with hitting the opponent, and the return to the "en garde" stance. Do and Yiou [2] as well as Hassan and Klauck [3] evaluated the fencing action technique with application of the EMG signal. The purpose of their study was to evaluate the speed of movements, the acceleration of lower limbs and the weapon arm, as well as the arm of force and angles of joints during the fencing lunge. The aim of this study was to determine the dynamic model of the fencing lunge, based on the EMG signal analysis from three key muscles: extensor carpi radialis of the right arm and musculus rectus femoris of both lower extremities. The objective of the analysis was to evaluate the EMG signal value $[\mu \mathrm{V}]$ and the duration [ms] of the muscles activation.

\section{Material and Methods}

The sportswoman selected for the tests was Magda Mroczkiewicz, a 31-year-old, right-handed, most experienced Polish foilist, the world and vice-Olympic champion in foil (height: $179 \mathrm{~cm}$, mass: $64 \mathrm{~kg}$ ). The athlete's task was to perform the fencing lunge ahead and return to the "en garde" stance, at her own pace, making her own choice with an emphasis on the quality of the action execution. Testing was conducted in the course of the preparatory camp for the starting season 2011, without using the weapon.

The testing tool applied was the EMG system of the Noraxon company, which records the bioelectric activity of muscles, the so-called dynamic EMG, in training conditions with the wired communication between preamplifiers and the signal collecting unit. The digital signal recording EMG data is sent using telemetric transmission to a computer. Three pairs of electrodes were placed between the motion point and tendon trailers, along the longitudinal axis of the muscle.

\section{Results}

During the fencing lunge, muscle activation starts with the rear lower extremity rectus femoris, and then after $112 \mathrm{~ms}$ the EMG stimulation rises in the attacking arm (Fig. 1). In $212 \mathrm{~ms}$, the front lower extremity stimulation occurs. Comparing the activity of rectus femoris muscles in both lower extremities, it can be observed that in the first phase of the leap, activation in the rear lower extremity muscle is larger, and its peak value is $178 \mu \mathrm{V}$, while in the front lower extremity this value is only $62 \mu \mathrm{V}$. In addition, during this phase, the left lower extremity muscle is also active longer, as its stimulation until the next activation takes $736 \mathrm{~ms}$, while in the right lower extremity muscle only $555 \mathrm{~ms}$. The largest stimulation in the front lower extremity occurs when the muscles brake the lunge and the curve peak value reaches $210 \mu \mathrm{V}$. At this moment the activation of the rear lower extremity is irregular, because the limb stabilizes the body. When the body returns from the fencing lunge, the front lower extremity is activated first as it strives to leap from the ground and its peak activation value is $183 \mu \mathrm{V}$. The curve peak value of the rear lower extremity is then $219 \mu \mathrm{V}$. The total time of the entire lunge was $2100 \mathrm{~ms}$. During the full move, the average activation in extensor carpi radialis was $69 \mu \mathrm{V}$, in rectus femoris of the front lower extremity it was $100 \mu \mathrm{V}$, and in rectus femoris of the rear lower extremity $105 \mu \mathrm{V}$.

\section{Discussion}

Testing demonstrated that the classical technique principles of the fencing lunge starting with the dominant arm was not confirmed. It is consistent with research of many authors, among others Lakisha and Vagenas [4]. This observation explains the tactics used by an experienced foilist, who anticipates the opponent's actions based on observation of the opponent's rear lower extremity.

Similar conclusions were also drawn during tests on the fencer's limbs acceleration [5]. Those results show that the acceleration of the arm occurs later than of the rear lower extremity.

Our study confirmed the observations made by many leading fencing coaches - foil specialists - that movement of the fencing lunge is initiated by the largest muscles of the rear lower extremity. 
During the full fencing lunge the arm somewhat precedes the front lower extremity fall and theoretically it should activate the referee's electrical signal equipment before the front lower extremity touches the piste. Due to the fact that the foil is a conventional weapon, in reality of the bout, athletes abuse the advantage of their own attack and intentionally delay the end of the attack to avoid the opponent's unexpected defence. Excessive delay of the decision to end one's own offensive action seemingly gives tactical advantage and exposes the contestant to the opponent's counterattacks.

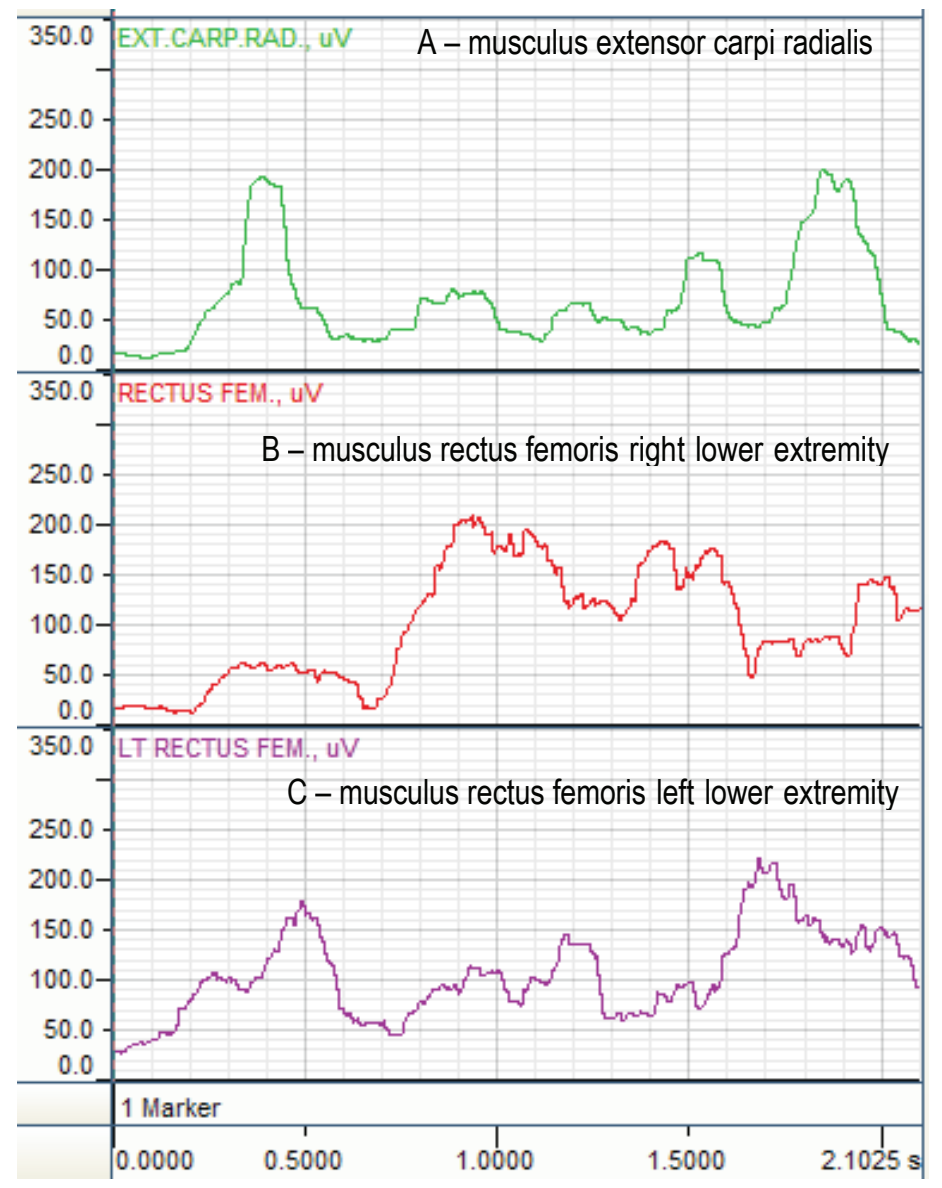

Fig. 1. Integrated EMG signal of three muscles during the fencing lunge

\section{Conclusions}

The dynamic model of the tested muscles activation during the fencing lunge is as follows: the rectus femoris muscle in the rear lower extremity is activated as the first one, then extensor carpi radialis of the weapon arm, and the front lower extremity rectus femoris is activated as the third one.

The overall configuration of the EMG curves indicates the synchronization of the right arm and left lower extremity muscle stimulation, especially active in the initial phase of the fencing lunge and before taking the "en garde" stance. Bioelectric tension of the front lower extremity showed the largest value in the middle phase of the lunge program performance, while other muscles were less active. It was observed that the attacking arm showed the highest EMG signal values at the beginning of lunge phase, after which the activation decreased with a slight increase at the moment of the hit.

The issue being the subject of the study requires further, thorough analysis in conditions similar to a real bout with application of a more sophisticated EMG system, which would have at least 8 channels. 


\section{References}

1. Borysiuk Z. Modern Saber Fencing. New York: SKA SwordPlay Books; 2009.

2. Do MC, Yiou E. Do centrally programmed anticipatory postural adjustments in fast stepping affect performance of an associated "Touche" movement? Exp Brain Res 1999;129(3):462-466.

3. Hassan EA, Klauck J. Kinematics of lower and upper extremity motions during the fencing lunge: results and training implications. In: Proceedings II. Köln: Deutsche Sporthochschule; 1998, 170-173.

4. Tsolakis Ch, Vagenas G. Anthropometric, physiological and performance characteristics of elite and subelite fencers. Journal of Human Kinetics 2010;23:89-95.

5. Zissu M, Silva C. Biomechanical model of the fencing lunge to the head in female sabre weapon. In: Book of abstracts: 1st International Congress on Science Technology in Fencing, Barcelona, 15-17 February. Barcelona, 2008, 98-99. 